\title{
QUALIDADE FÍSICO-QUÍMICA E MICROBIOLÓGICA DE BEBIDAS LÁCTEAS UAT COMERCIALIZADAS EM VIÇOSA-MG
}

\author{
(Physical-chemical and microbiological quality of UAT dairy drink commercialized in Viçosa-MG) \\ ${ }^{1}$ Ana Carolina Gomes Domingos, ${ }^{2}$ Guilherme Ferraz Rodrigues, ${ }^{2}$ Adriano França da Cunha, ${ }^{2}$ Alexandre Alves \\ Lustosa, ${ }^{2}$ Janilson Alves Silva, ${ }^{2}$ Letícia da Silva Neves, ${ }^{2}$ Henrique Cotta Brum Ribeiro, ${ }^{2}$ Bernardo Lacerda Matias \\ Rodrigues
}

${ }^{1}$ Universidade Federal de Viçosa (UFV), Viçosa, Minas Gerais, Brasil. ${ }^{2}$ Centro Universitário de Viçosa (UNIVIÇOSA), Viçosa, Minas Gerais, Brasil.

*Correspondência: carolina.gomesdomingos@gmail.com

RESUMO: A bebida láctea é obtida da mistura de leite e soro de leite, fermentada ou não, e que pode comprometer a saúde do consumidor. Além disto, há risco de serem produzidas com soro contendo nitrato e nitrito devido a utilização de tais conservantes na fabricação de queijos. Portanto, o objetivo do trabalho foi avaliar a qualidade microbiológica e físico-química em quatro marcas de bebidas lácteas UAT comercializadas na cidade de Viçosa (MG). Cinco lotes de cada marca foram avaliados quanto à contagem de mesófilos, coliformes totais e termotolerantes, fungos, Staphylococcus spp., pesquisa de Salmonella spp. e quanto aos teores de proteína e gordura de acordo com metodologias do Ministério da Agricultura, Pecuária e Abastecimento (MAPA). Os teores de nitrato e nitrito foram determinados de acordo com metodologia adaptada do MAPA para bebidas lácteas. Os resultados foram analisados de forma descritiva de acordo com os parâmetros legais estabelecidos pela legislação brasileira. Nenhuma amostra apresentou contagem de mesófilos, coliformes, fungos, Salmonella spp. e Staphylococcus spp., o que sugere que há controle de contaminação industrial e qualidade da matéria prima. Além disso, os produtos não foram violados durante o transporte e armazenamento, tanto na indústria quanto nos supermercados. Uma (5\%) e $16(80 \%)$ amostras apresentaram teores de proteína e gordura abaixo dos limites mínimos de $1 \mathrm{~g} / 100 \mathrm{~g}$ e $2 \mathrm{~g} / 100 \mathrm{~g}$, respectivamente. Alterações nos teores sólidos se devem às variadas técnicas de processamento, uso de leite e soro de diferentes composições e à proporção de ingredientes não lácteos adicionados. Nenhuma amostra apresentou resultado positivo na prova de nitrito ou nitrato, o que sugere que as indústrias possuem controle de produção e qualidade do soro quanto à presença de tais conservantes. Portanto, bebidas lácteas de Viçosa (MG) possuem boa qualidade microbiológica e não apresentam nitrato e nitrito. Entretanto, as marcas avaliadas apresentam teores de gordura e proteína em desconformidade com a legislação.

Palavras-chave: composição; conservantes; legislação; soro.

\section{Nota}

A pesquisa foi aprovada pelo Núcleo de Pesquisa e Extensão (NUPEX) do Centro Universitário de Viçosa (UNIVIÇOSA) sob o número de protocolo 258.2019.01.01.15.03. 